\title{
OTHER LUNG DISEASES DUE TO DUST
}

\author{
By A. T. DoIG, M.D., D.P.H. \\ H.M. Medical Inspector of Factories
}

\begin{abstract}
Respiratory dust disease until comparatively recently was commonly thought of as comprising little more than silicosis and asbestosis. In the last decade, however, there has been general appreciation of the fact that the field is considerably wider. Silicosis, asbestosis and pneumoconiosis of coal miners and coal trimmers have been described in this issue and the author has been invited to deal with the remaining dust diseases of the lungs. To do so in detail in this article is impossible. His object will be to indicate something of the scope of the subject dealing only briefly with the individual dusts and the conditions they cause. The references which are given have been chosen with a view to forming a starting point for further reading about the effects of individual dusts.
\end{abstract}

\section{Mineral Dust}

\section{Pneumoconiosis with Fibrosis}

Although silica, asbestos and coal are the most important dusts which cause pulmonary fibrosis, there are others which have a similar effect. Many of these are mixed dusts, containing several constituents, and in the case of naturally occurring minerals some proportion of free silica is generally present. In such cases it has to be considered whether the condition produced is due to the action of silica modified by other dusts present. It is often impossible to state definitely whether this is so or whether the other constituents of the dust also exert a toxic effect, but there is certainly a growing amount of evidence that some materials which were formerly considered innocuous are either by their own property or by virtue of admixed silica, capable of causing lung disease on inhalation.

SiliCates: For long asbestos was considered the only harmful variety of silicate, and other silicates such as talc were regarded as inert. Merewether (1933) examined I I workers exposed to the inhalation of talc dust for periods ranging from I I to 32 years, and in 1934 he examined a further I 3 workers with exposures of from $4 \frac{1}{2}$ months to 40 years. He found abnormal appearances in the X-ray films of the chests but that these were associated with little or no clinical disability. Although this was the first in this country there had been earlier reports from the Continent suggesting the existence of a talc pneumoconiosis. Since 1933 also there have been many reports from America of cases of injury to the lungs from talc, based not only on X-ray appearances but on the existence of symptoms, of abnormal signs on clinical examination of the chest, of disability and, in some cases, on post mortem findings. In this connection it is interesting to note that talc has been implicated in the causation of peritoneal adhesions after abdominal operations. An editorial with references to ten articles dealing with this subject appeared in the British Medical Fournal in I948. McLaughlin, Rogers and Dunham (I949) have recently described in great detail a fatal case of talc pneumoconiosis occurring in this country. They also review the literature on this interesting and important subject.

Although admixture with quartz up to 20 per cent. has been reported in some American talcs, ordinary commercial talc as used in this country is silica-free as was the talc used by the patient of McLaughlin, Rogers and Dunhain. Under the microscope talc is seen to exist both as flakes of material and tiny fibres. McLaughlin and his colleagues suggest that the fibrosis is produced mainly or only by the fibres. Not only was the fibrosis similar to that of asbestosis but an interesting feature was the presence of curious bodies similar to asbestos bodies. It seems therefore that we must accept talc as a fibrosis-producing agent and institute means of dust suppression where there is considerable exposure to it.

A disabling type of pneumoconiosis due to Fuller's earth has also been reported (Middleton, 1940; McNally and Trostler, I94I). Tonning (1949) recently described the post mortem appearances of a man aged 79 who had worked with Fuller's earth in his youth. 'The exact length of his employment was unknown but it had ceased about the age of 29, and so probably did not exceed 15 years. Thereafter he had no dust exposure at work. The lungs were moderately emphysematous and contained numerous black firm nodules. Microscopically the dust was seen to be held in a loose mesh of fine reticular fibres and the lesions were invariably surrounded by emphysema. The histological picture differed from typical 
silicosis in an absence of the whorled collagenous nodules and closely simulated that of pneumoconiosis of coal miners with focal emphysema round the dust aggregations.

The position in regard to other silicates is less definite. Lung injury has been described following inhalation of mica, china clay, sillimanite, sericite, etc. For some years following 1933, a great controversy raged about sericite following the assertion by W. R. Jones (1933) that silicosis was due not to free silica (quartz) but to sericite which is a silicate of aluminium and sodium. This theory has now been proved to be without foundation and has been abandoned. Nevertheless there is some experimental evidence that sericite is by itself harmful.

The use of grinding wheels made of natural sandstone was attended with a very high incidence of silicosis, but now they have practically disappeared their place being taken by manufactured wheels made of carborundum, emery or some forms of aluminium oxide. This has been accompanied by a marked decline in the number of cases of silicosis in the grinding industry. It is possible, however, that under certain circumstances, carborundum, which is silicon carbide, may not be entirely harmless. Some surveys of workers employed grinding metals with artificial abrasive wheels have shown the presence of nodular shadows on the X-ray film, and while these may have been due to particles of the metal being ground, particles of the abrasive wheel could not be excluded. Recently at a factory handling powdered silicon carbide and aluminium oxide in such a way that considerable quantities of dust were created, 53 employees were examined radiologically. Fifteen films were stated to show some pulmonary fibrosis which in seven was of a nodular type resembling silicosis, but three of these cases had substantial previous exposures to mineral dusts (Smith and Perina, 1948).

Aluminium: Considerable interest has arisen in the possible action of aluminium and its oxides on pulmonary tissue, and reports in the literature are conflicting. On the one hand we have very strong evidence that finely powdered aluminium or aluminium oxide even when present in a concentration of only I per cent. has a powerful inhibitory action on quartz, protecting experimental animals from silicosis. This work first reported from Canada (Denny, Robson and Irwin, 1937) has since been widely confirmed not only for metallic aluminium, but also for aluminium hydrate (Gardner et al., 1944). On the other hand we have reports that workers exposed to finelydivided metallic aluminium or its compounds may suffer chronic respiratory disease. Such reports appeared in the Continental literature about $194^{\circ}$
(Goralewski, I940, I94I ; Goralewski and Jager, I94I ; Jager and Jager, I 94I ; Jottert and Eickhoff, ֵֶِ 1942, etc.). A type of pneumoconiosis has been 3 reported in furnace workers exposed to the volatilized fumes of alumina (Shaver and Riddell, $\stackrel{\complement}{\subset}$ 1947). Several cases were found to have $a=$ spontaneous pneumothorax, a feature which had $\stackrel{\text { ? }}{\rightarrow}$ already been noted by the German workers. Experiments in animals have suggested that aluminium may favour the development of $\frac{\bar{c}}{\vec{D}}$ tuberculosis in the lungs. The whole question is $\propto$ being thoroughly investigated in this country and abroad, and until definite results are obtained it $\vec{\circ}$ would seem reasonable to consider that prolonged $\stackrel{\circ}{-}$ exposure to finely-divided particles of aluminium $\vec{\omega}$ or aluminium oxide dust may be harmful.

GRAPHITE: Graphite is a naturally occurring crystalline form of carbon, although a pulverized 3 . form of coke is also called graphite. Natural graphite consists of carbon mixed with other minerals and after incineration may leave as much: as 33 per cent. ash. According to Harding and क्षे Oliver (1949) various graphites contain 8 to $18.6^{\circ}$

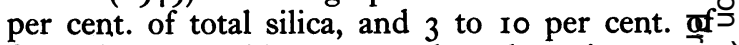
free silica. In this country there have in rece ${ }_{0}-$ years been several reports of serious lung disease caused by graphite dust. Dunner (1945), Dunngr and Bagnall (1946), and Dunner (1948) recoud five cases of graphite pneumoconiosis. Two fatal $\stackrel{\Phi}{-}$ cases with detailed post mortem findings were re- $\overrightarrow{0}$ ported by Gloyne and others (1949) and a most interesting observation in one of their cases was the finding of golden yellow 'graphite bodies' similar to the 'asbestosis bodies' of asbestos workers and ' anthracosis bodies' of coal miners. Harding and Oliver (1949) record three fatal $\stackrel{\circ}{\mathbb{Q}}$ cases and give brief notes of six workers who $\stackrel{\varrho}{\vec{Q}}$ showed X-ray changes. They point out that graphite pneumoconiosis is not the benign con- 3 dition it has in the past been assumed to be; it can on the contrary lead to complete incapacity and death. Histologically the lesions they describe $\frac{0}{3}$ are similar to those of coal miners, with pigment: aggregates, linear or radial fibrosis and focal 3 . emphysema. In advanced cases massive fibrosis occurs without definite nodule formation.

\section{Pneumoconiosis without Fibrosis}

Certain dusts, among them iron and tin, seemo to be inert when inhaled: The particles, provided they are small enough to enter the alveoli areos engulfed in phagocytes, some of which are coughedn up, while others are deposited in the aggregations of lymphoid tissue at the bifurcations of the $\omega$ bronchioles. They are capable of lying there for years without inducing any deposition of fibrous $\frac{0}{\varnothing}$ tissue or other reaction, but because they are relatively opaque to the $\mathrm{X}$-rays they may produce 


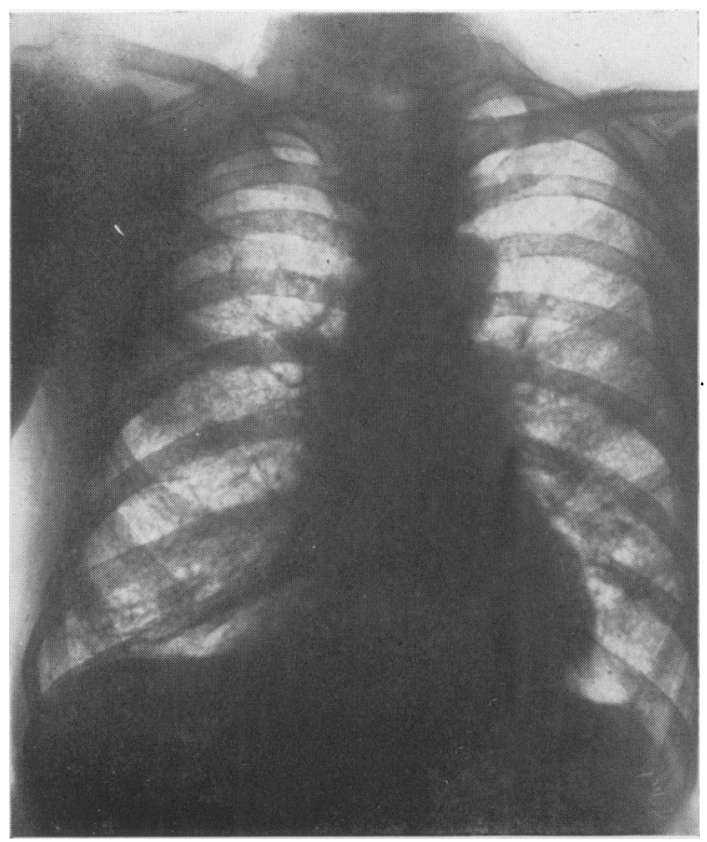

FIG. 1.-A.T.T., worker with Fuller's earth for 35 years (Dr. Middleton's case).

changes in the X-ray film which may be indistinguishable from those of silicosis. Opportunities for inhaling iron oxide dust occur in many occupations and it is most important that the condition produced should be correctly assessed. Reticulation or nodulation on an X-ray film of the chest does not mean fibrosis or disease, and many a worker has passed through a very unhappy period after being told he was suffering from silicosis when, in fact, he was merely exhibiting a dusting or tattooing of his lungs with iron oxide.

Such X-ray films are frequently met with in welders who are constantly exposed to fumes from the work. The heat of the electric arc or the oxyacetylene torch melts and boils the metal being welded, iron coming off as a vapour and oxidizing almost immediately to iron oxide in minute particles. Welders who have spent years at this work, particularly if they have performed substantial amounts of welding inside boilers, tanks and other ill-ventilated spaces may be found on $\mathrm{X}$-ray examination to show reticulation or nodulation.

The condition was first described by Doig and McLaughlin in 1936 , and at that time we were not sure what was the cause or the outlook for the patient. We did, however, emphasize that the X-ray changes we described occurred in

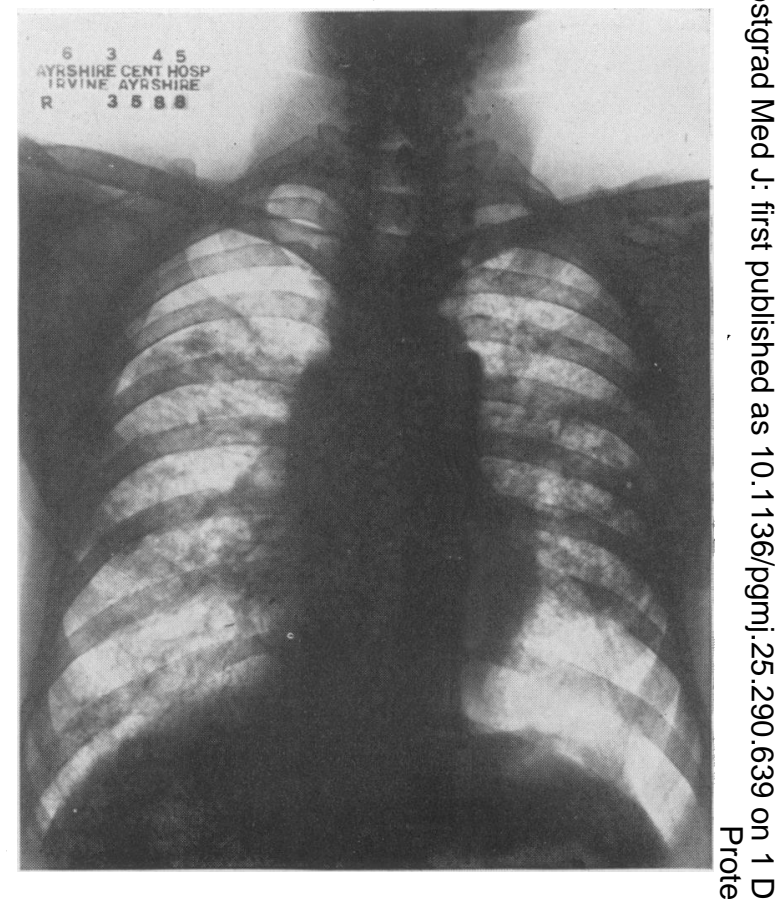

Fig. 2.-A.M., aged 40. Dyspnoea after exposure t尺 fireclay dust during 13 years cutting and grinding $\frac{\mathbb{Q}}{3}$ bricks.

men who were apparently in good health. Furthex $\frac{8}{0}$ experience by clinical examinations of some hundreds of welders has made us certain that the condition is benign and not accompanied by symptoms, abnormal physical signs or diminished capacity for work.

Some welders with dust reticulation have been re-examined at intervals up to 14 years and found to remain quite fit and continue at work without any difficulty. The X-ray changes are not associated with dyspnoea or clinical evidence of fibrosis. Chest expansion is good and tolerance for exercise is normal. These findings have been amply confirmed by numerous investigators not only as regards welders (Britton and Walsh, 1940; Groh, 1944; Sander, 1944; Lanza, 1945, etc.) but also as regards other workers exposed to iron oxide such as silver finishers (McLaughlin et al., 1945; Barrie and Harding, 1947).

As has been stated the X-ray picture in this condition is identical with silicosis and examination of a single X-ray film does not supply evidence of the inert nature of the condition. Serial X-rays taken over a period of years, particularly after exposure to welding has ceased may, however, give supporting evidence. $\mathrm{X}$-ray changes in silicosis are permanent; if they change it is for the worse, indicating a progression of the process, and such a 


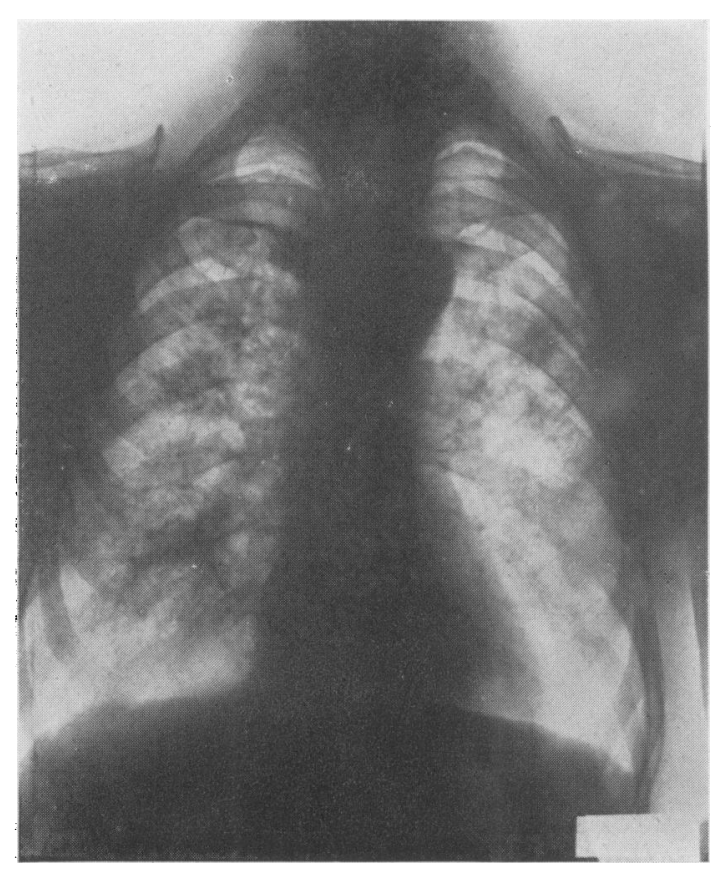

Fig. 3.- J.M., aged 65. Exposure to 'carbon' dust consisting mainly of ground coke for 30 years. Moderate dyspnoea.

change is unfortunately commonly met with. Improvement in the X-ray appearances has not been described nor is it to be expected in a disease characterized by the laying down of a considerable amount of fibrous tissue. On the other hand Doig and McLaughlin (1948) have described two of our original welders whose X-ray appearances changed for the better, and indeed in one case the picture returned to normal some years after giving up welding. Such an observation is only compatible, to our minds, with a condition in which the dust lies amongst normal tissue and is not shut in by fibrous tissue or associated with other changes of a permanent nature.

There is only one report in the literature of a post mortem examination of a welder who showed $\mathrm{X}$-ray changes of the dust inhalation type during life (Enzer and Sander, 1938). This is illustrated by excellent photomicrographs showing no fibrosis round the collections of dust which were found to give the Prussian blue reaction. The man's death was not related to his occupation or his lung condition but was the result of an accident. In successive papers McLaughlin and his colleagues (1945), Barrie and Harding (1947), and Harding (1948) describe the post mortem findings in five

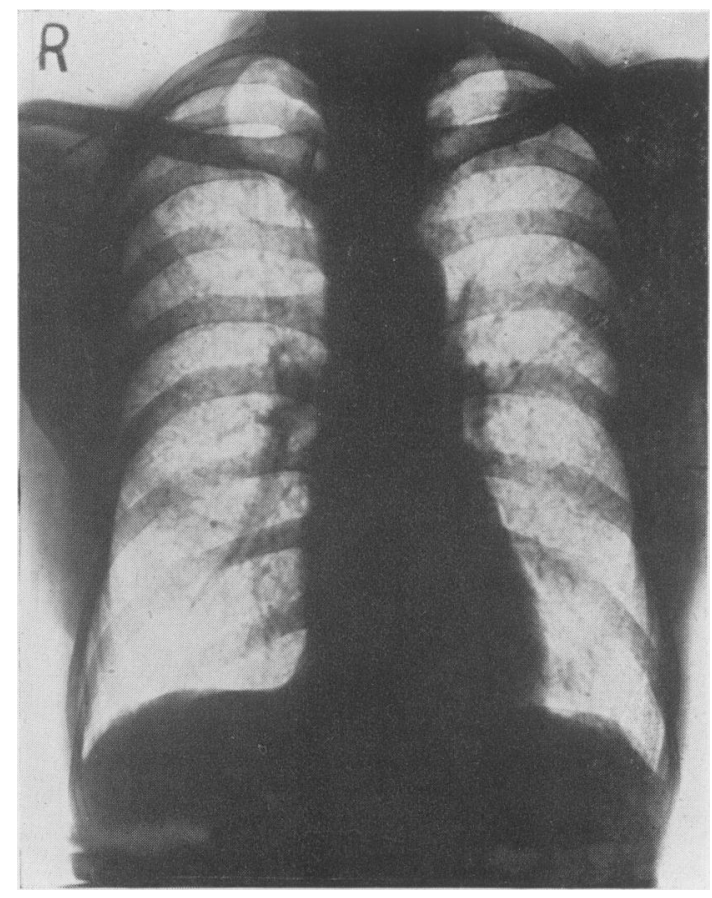

FIG. 4.-F.G., aged 52. Electric welder 30 years, oxy-@ acetylene welder three years. X-ray appearances $\sigma$ unchanged over nine years. Remains symptomless $\cap$ (D) and at work.

silver finishers who showed during life the typical $\mathrm{X}$-ray changes of dust-deposition in the lungs. In the first four cases there was absolutely no fibrosis round the deposits of iron oxide. In the fifth case there was a minimal amount of fibrosis of the ' reticulation type'-not at all like that produced by silica. Harding thinks that in this case individual susceptibility may have been of importance, but there is always the possibility that the iron dust at some period of the man's working life-over 40 years-may have contained silica or other fibrosis-producing-constituent. Indeed it is not without the bounds of possibility that he may have used sand as the polishing medium at one time. The author has himself seen sand used for this purpose in a Sheffield polishing shop in 1939 .

Further evidence of the inert behaviour of iron oxide has been obtained from animal experiments which have been carried out by numerous observers, for example, Harding, Grout and Lloyd Davies (1947) who produced X-ray changes in the lungs of rats exposed to iron oxide dust but examination of the tissues showed no fibrotic or 2 other reaction. Finally there is statistical evidence. The Registrar General's Supplementary Report on Occupational Mortality, I93I, shows that of 


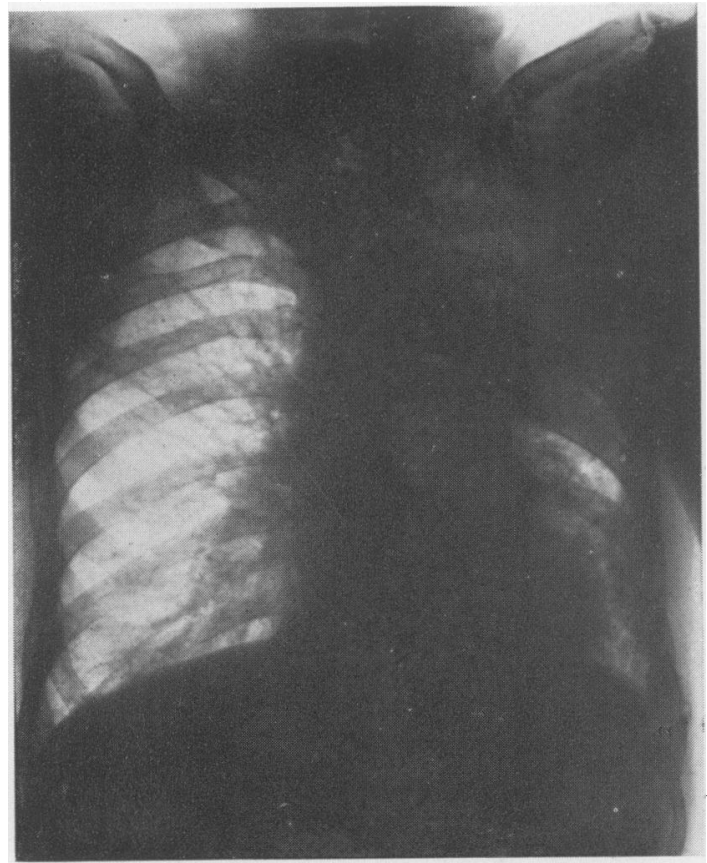

FIG. 5.-J.W.I., aged 53. Bronchial carcinoma associated with early asbestosis (confirmed at autopsy) in an asbestos weaver (Dr. F. N. R. Price's case).

the 11,542 welders in England and Wales in that year there were only 123 deaths compared with I6r expected on the basis of age-rates for all males. The author has collected from various factories information about sickness absence in welders and find that they are favourably placed as regards other groups, not only for total sickness but also for sickness due to respiratory disease. Collen and his colleagues (1944) and Collen (1947) give reliable evidence about the incidence of pneumonia in welders, showing that the incidence, death rates and case fatality rates for welders in the Kaiser-Oregon shipyards were similar to all other shipyard workers and that there was no difference in severity, number of days required for treatment or the incidence of complications.

Taking all the evidence then there seems to be proof that iron oxide, inhaled into the lungs in amounts sufficient to give rise to changes on the $\mathrm{X}$-ray film, lies inertly in the tissues for years without giving rise to pulmonary fibrosis or other permanent change.

Other dusts which are considered on present evidence to be inert in the lungs include barium, calcium and tin. In 1933 Arrigoni carried out an enquiry amongst the barium workers at Valsassina in Italy. He found that many men, particularly

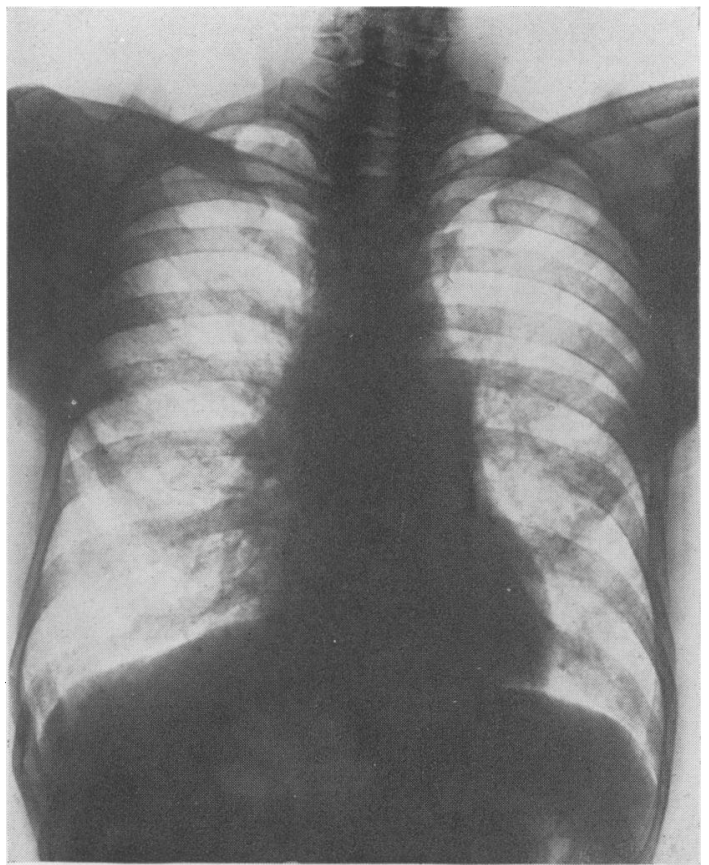

FIG. 6.-Hayworker's lung (Dr. J. M. Campbell's case). Extreme dyspnoea, eventual recovery.

grinders and packers, showed marked changes iro the X-ray films but that symptoms and abnormaF clinical signs were slight or absent. Tin, like barium, is much more radio-opaque than iron and therefore deposits in the lungs cause particularly dense shadows. Pendergrass and Pryde (I948) reproduce an excellent X-ray of this type, the subject being a man aged 45 years who had bagged tin oxide for 15 years. He had no disability, the X-ray abnormality being discovered during a routine survey of all the workpeople. Workers exposed to lime, gypsum or marble dusts do not appear to suffer any harmful effects and while X-ray abnormalities indicating dust deposition have been met with, these are generally comparatively slight in degree (I.L.O., 1938). The manufacture of cement, which is a complex compound of lime, is usually attended with exposure to considerable quantities of dust. Cement is irritating to the skin and mildly to the upper respiratory passages. It cannot be regarded as an inert dust yet there is a considerable body of evidence which suggests that workers manufacturing or handling cement do not get pneumoconiosis. For instance, Gardner and others examined and X-rayed 2,278 workers in 1939. Over 55 per cent. of the group had been exposed for 


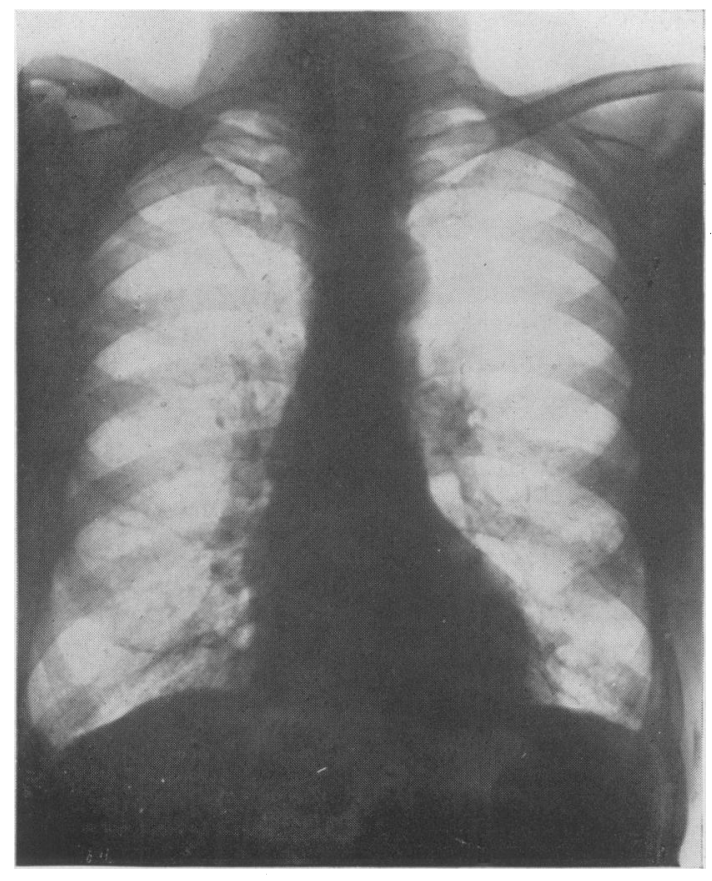

FIG. 7.-A.L., aged 57. Byssinosis. Stripper and grinder in a cotton mill for 40 years (Dr. F. N. R. Price's case).

more than ten years, but no cases of disability were met with and X-ray abnormalities were of the slightest. The authors consider the dust risk in the cement industry as trivial compared with rock mining and other silica industries.

\section{Pneumonitis}

The dust or fume from some metallic compounds is directly irritating to the lung parenchyma and leads to atypical forms of pneumonia usually spoken of as pneumonitis.

Manganese, as is well-known, may cause a chronic disease of the nervous system. Since 1921 there has also been suspected a relation between manganese and pneumonia. At Sauda, in Norway, the installation of a manganese smelting factory was followed by a tenfold increase in the mortality rate for pneumonia. Similar reports have been made in regard to workers in German factories, and miners of the ore. In this country Lloyd Davies (1946) showed that a group of men exposed to oxides of manganese existing as fine particles in the air had, between 1938 and 1945, a pneumonia rate of 20 to 90 times that of other workers in the factory. The cases usually resolved without leaving any disability, but compared with nonindustrial pneumonia resolution was slower and

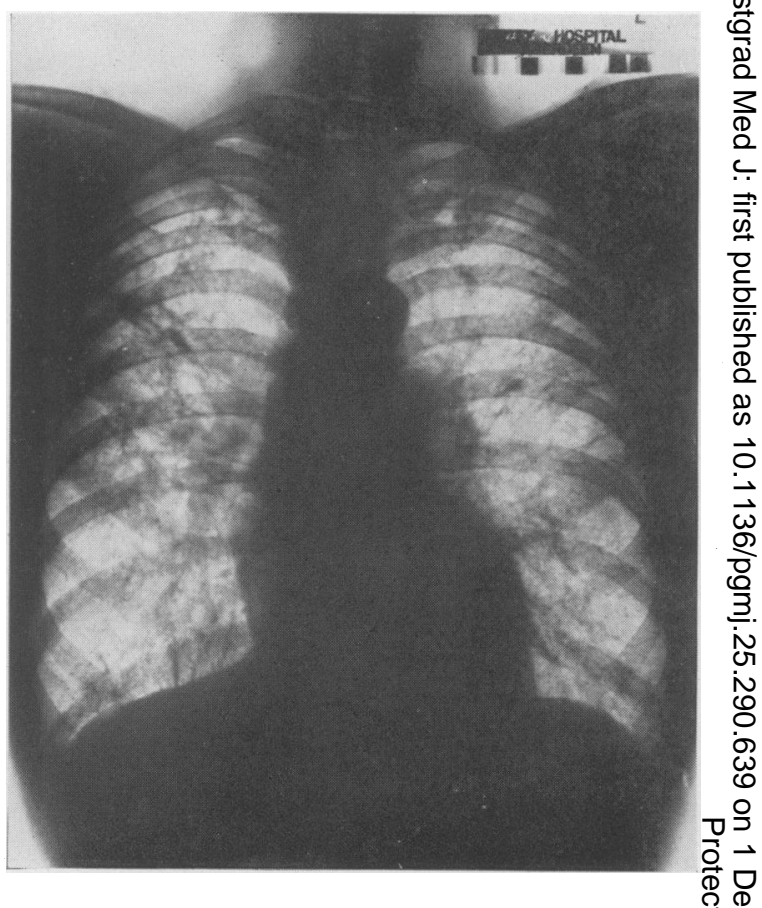

FIG. 8.-Pulmonary fibrosis and dyspnoea in a man $\frac{\overrightarrow{\mathbb{D}}}{\mathbb{D}}$ aged 46, engaged in tea blending for five years with $\sigma \bar{\sigma}$ no other dust exposure (Dr. Douglas Bell's case).

less influenced by sulphonamides. In a later rê․ port Lloyd Davies and Harding (1949) make further observations including the results of animal experiments. The changes in the bronchial and $\bar{D}$ alveolar epithelium are well illustrated with photo- $\frac{\mathscr{Q}}{\Phi}$ micrographs. It has been stated that some other $\cong$ factor is necessary in addition to manganese before $\overrightarrow{\overrightarrow{0}}$ pneumonitis results, but these authors conclude 3 that manganese dust in suitable particle size, introduced into the respiratory system, will without the presence of other factors, cause pneumonitis.

Beryllium is a metal which has become of considerable importance in recent years. Inhalation $\frac{5}{3}$ of its compounds in a fine state of division is known to cause pneumonitis. First reports of this con- $\frac{O}{3}$ dition came from Russia in 1936, relating to workers exposed to beryllium oxyfluoride, and the $\frac{5}{5}$ irritant action was at first thought to be due to the $\frac{D}{0}$ fluorine. The literature on the toxic action of beryllium is now extensive and it is recognized that $N$ non-fluorine containing compounds are generally $\mathrm{N}$ just as toxic. The production and use of beryllium and its compounds in Britain lags behind the $\omega$ United States, where numerous reports of pneumonitis from beryllium have appeared. What seems to be the first record of such a case in this country is that of Royston (1949). 
Cadmium fumes are particularly irritating and may cause a severe pulmonary reaction. Pneumonitis may also follow exposure to the fumes of osmium and vanadium.

\section{Delayed Pneumonitis (Granulomatosis)}

Another type of pulmonary reaction has been observed in persons exposed to beryllium. This comes on after a more prolonged period of contact, and sometimes months or years after contact has ceased. It has been particularly associated with the manufacture of fluorescent lamps in which a zinc beryllium silicate was often used. The first report (Hardy and Tabershaw, 1946) concerned 17 cases in workers in the fluorescent lamp industry among whom there were six deaths. The symptoms were loss of appetite, loss of weight, marked dyspnoea, cough and weakness, and a feature was a tendency to progression after removal of contact, unlike the acute pneumonitis which was usually ameliorated by removal from the industrial exposure. X-ray changes are variable but usually consist of granularity, reticulation or nodulation. The illness shows a marked similarity to sarcoidosis; indeed the late Leroy Gardner reported in 1946 that he had in his files some roo cases of sarcoidosis of which 60 were known to have exposure to beryllium. This particular lesion caused by beryllium is neither a true pneumonitis nor a pneumoconiosis; the lung changes are only part of a general pathological condition characterized by granulomata in various organs including the liver, spleen and sometimes the lymph glands. In this country only one case has so far been described (Agate, 1948).

\section{Lung Cancer}

It is now known that the incidence of cancer of the lung in certain occupations is sufficiently high to suggest a significant etiological relationship between the disease and the occupation. The best example is probably that of the Schneeberg miners in Saxony who for four centuries have been known to die at a comparatively early age from lung disease which Harting and Hesse in 1879 showed was pulmonary carcinoma. They attributed 75 per cent. of all deaths of the miners to this cause. later a high incidence of lung cancer was also discovered in mines of Joachimstal in Bohemia on the other side of the mountains. The actual cause of the condition is not certain as the ore contains several suspected substances. At first cobalt was mined in the form of its arsenide, later bismuth and nickel and, finally, uranium. Arsenic or radio-activity are both considered likely causes.

We also have evidence in this country that arsenic may lead to lung tumours although no excess of this disease has been noted in miners of tin ore which contains arsenic. Several cases in factory workers exposed to arsenic dust have been noted by the Factory Inspectorate who, in 1945 , referred the question of the etiological relationship of arsenic and cancer to the Medical Research Council. A detailed investigation was carried out and it was found that workers exposed to arsenic showed a significant excess of deaths from cancer over other occupational groups and that there was an especial predilection for cancer of the skin and lungs (Bradford, Hill and Fanning, I948). The role of arsenic in carcinogenesis has been dealt with by Currie (1947).

Amor (1938) has reported a high incidence of cancer of the lung and upper respiratory tract in nickel smelters. Here again there is exposure to arsenic which is present in the ore. In this country chromium has not so far been found to have a carcinogenic effect and the report by Teleky in I937 that inhalation of chromate dust produced a relatively high incidence of lung cancer does not seem to have evoked much interest or comment at the time. After the war however, reports of a high incidence of lung cancer in bichromate manufacture were received from Germany (Gross and Koelsch, 1943); and confirmation has now been forthcoming by the researches of Machle and Gregorius (1948) in America who showed that workers in the chromate industry had a crude death rate 25 times the normal and that 25 per cent. of all deaths were due to this cause. In the group of workers under 50 years of age, the rates for lung cancer varied in the different factories from 20 to 70 times that of the general population in the same age-group.

Some ten years ago a number of cases of lung cancer occurring in men suffering from silicosis were reported and an impression arose that silica might play an etiological part in producing malignant lung disease. This has not been borne out by further enquiry but evidence is accumulating that cancer of the lung is unduly frequent in asbestos workers usually associated with asbestosis. Merewether (1949) has reported that cancer of the lung or pleura occurred in 31 ( 13.2 per cent.) of 235 cases of asbestosis, in which post-mortem examinations were made, whereas in 6,884 cases of silicosis proved at autopsy there were only $9 \mathrm{I}$ cases (I.32 per cent.).

\section{Asthma}

Asthma due to purely inorganic dusts is not common. Hunter, Milton and Perry (1945) examined workers in all the platinum refineries in Britain and found that of $9 \mathrm{I}$ who had contact with certain complex platinum salts, 52 suffered from a peculiar asthma-like syndrome. Repeated sneezing was followed by profuse watery discharge from 
the nose, tightness of the chest, shortness of breath and wheezing. These symptoms persisted during work and for about an hour after when they would subside. Commonly, however, a bout of coughing was experienced in the early hours of the morning.

\section{Vegetable Dusts}

Vegetable dusts are of less importance than mineral dusts but their ability to produce respiratory disease is by no means small. The study of their effects has been largely neglected and their importance probably underrated. This is partly, at least, due to the fact that the condition of chronic bronchitis which sometimes results from their prolonged inhalation is not accompanied by any characteristic X-ray picture indicative of dust inhalation, as in the case with the pneumoconiosis due to mineral dusts. The chronic effects of vegetable dusts are thus less easily distinguished from non-occupational bronchitis.

Vegetable dusts lead to acute, sub-acute and chronic pulmonary conditions. Their mode of action is obscure and in many cases it is not known whether the noxious agent lies in the vegetable matter itself, for instance some protein, alkaloid or other active principle which is irritating or toxic, or whether it lies in the impurities. In regard to chronic disease silica has been considered, for free silica derived from soil is a universal contaminant of vegetable material. The amount present, however, is small, generally about 2 per cent. or less, and most of it is present as relatively coarse grains, so that it is not generally thought likely that silica plays any part in the production of lung disease from vegetable dust. The biological contaminants are more important. Vegetable matter almost always contains a high content of bacteria, and spores and mycelia of fungi, some of which are known to be pathogenic, and it is exceedingly likely that some types of pulmonary disease result from the bacteria or fungi in the dust. Another possibility is that the biological contaminants may act indirectly, not by themselves infecting the respiratory tract, but by their digestive action on cellulose or other constituent of the vegetable matter, altering it to form toxic substances. Again some conditions produced by exposure to vegetable dusts are obviously allergic in character. One must also consider a mechanical action. McNair and Middleton (1924), for example, were impressed with the fact that dust from most kinds of grain contained a considerable quantity of sharp stiff hairs and they believed that these constituted the harmful part of the dust. Another possible explanation is that dry vegetable matter on inhalation readily swells and this might result in small areas of atelectasis prone to become secondarily infected.
It seems that vegetable dusts more than minerasto dusts have a common type of action. In other总 words, whereas silica produces a nodular fibrosis beryllium a granuloma and arsenic malignant $\frac{\mathbb{Q}}{\mathscr{C}}$ disease, most vegetable dusts, grain, hemp, flax, cotton, etc., may cause mill fever, or result, after $\Rightarrow$ years of exposure, in a similar type of chronic bronchitis and emphysema.

\section{Mill Fever}

This is an acute, transient and slight illness occurring only in new workers. It usually comeses on after one or two days in the mill, lasts a day or two and does not reappear; one attack confersimmunity. It usually takes the form of a chill, $\vec{\omega}$ with fever, headache, lassitude and malaise, ando occasionally there may be respiratory symptoms $\frac{0}{3}$ such as sneezing, cough and dryness of the throat Often the symptoms are not sufficiently severe too necessitate absence from work but if any time is lost it is only a day or two. This curious little. illness has several names according to the duste్ producing it - ' combers' fever' in hemp mills, ' hackling fever' and 'flax fever' in flax milis, ' mill fever' and 'cotton cold' in cotton mile ' grain fever,' ' malt fever,' etc. It is uncertaqn whether an attack caused by one dust confexs immunity to. some other vegetable dusts, butg have known several workers who had experiencegl mill fever from jute and who suffered no illness $\overrightarrow{\text { Qr}} \overrightarrow{0}$ discomfort on later working in flax mills. 흐.

The condition is of little importance, severe cases and complications being apparently unknown. Probably between 25 and 50 per cent. of new workers in the flax industry suffer from itg today. The cause is unknown. Various sug- $\frac{2}{\mathbb{Q}}$ gestions made include the action of a foreign $\stackrel{2}{\vec{B}}$ protein, histamine, a bacterial endotoxin and $\frac{\overrightarrow{0}}{3}$ allergy.

\section{Illness due to Fungi and Bacteria}

In many respiratory diseases, particularly the $\frac{\overline{0}}{3}$ subacute or chronic types, saprophytic bacteria or fungi commonly exist in the sputum, and it is 3 . obviously no easy matter to decide whether a $\delta$ particular organism is present as a primary or secondary infecting agent. There is, however, ao group of respiratory diseases which we believe are due to fungi or bacteria, not merely because these을. are found in the sputum, but because the illnesses occur in small outbreaks associated with exposure? to dust from mouldy or infected vegetable matter. N

From time to time outbreaks of an acute illness called 'weaver's cough' have occurred in cottong weaving sheds (Collis, 1913; Bridge, 1928). These outbreaks have always been associated with $\frac{\bar{\Phi}}{\mathrm{D}}$ the handling of mildewed yarn, usually the warp $\stackrel{?}{?}$ which is more heavily sized tban the weft. The 
illness starts with irritation of the nose and throat, tightness in the chest, then follows paroxysmal cough, scanty tenacious sputum and general malaise. After removal from the weaving shed the acute symptoms rapidly subside but frequently a liability to bouts of coughing persists for some weeks. The association of the illness with the handling of mildewed yarn and its absence in workers even in the same factory who handled non-mildewed yarn points very strongly to a mildew as the cause. The air over the looms using the affected yarn was found to contain many fragments of mycelia and conidia, and examination of the dust and of the yarn revealed the presence of various fungi including penicillium, aspergillus, mucor and others.

Campbell (1932) described "cases of an acute but more severe illness in farm workers who had been handling mouldy hay. After some noticeable shortness of breath for days or weeks the affected workers became incapacitated with extreme dyspnoea and cyanosis. X-ray films showed a fine granular stippling and some ' fibrosis' spreading from the hilum. The symptoms lasted for weeks or months before slowly passing away in conjunction with a slow resolution of the X-ray changes. Fawcitt (1936) describes other cases including post mortem findings in one case in which there was at first partial recovery, but dyspnoea persisted and death took place two years after the acute illness. The lungs showed much emphysema, collapsed areas and marked patchy fibrosis. Potassium iodide is said to be useful in treatment.

Similar severe illness has occurred after threshing mouldy grain (Tornell, 1946; Hoffmann, 1946), and in the sawing of maple logs which had lain for a year or two after felling and become heavily infected under the bark with a fungus (conosporium corticale) (Towey, 1932).

It seems probable that bagassosis should also be placed in this group. Bagasse is dried sugar cane after extraction of the sugar and is imported for use in the manufacture of fibre boards for decorating and insulating purposes. It is an excellent growth medium for a great variety of bacteria and fungi. On leaving America it has a glucose content of 2 or even 4 per cent., but on reaching this country it is nearly sugar-free. Several cases of acute or subacute bronchiolitis or bronchopneumonia have occurred and have been reported in this country and America. Hunter and Perry (1946) give an excellent review of the literature and describe I I cases of their own, one of which was fatal. The evidence that the disease is due to fungi, though suggestive, is not conclusive; Schneiter, Reinhart and Caminita (1948) think it is due to the endotoxin of Aerobacter Cloacae.

\section{Monday Fever}

This term was introduced by Prausnitz (1936), but numerous observers before him had described an aggravation of respiratory symptoms on Mondays. It is quite different from mill fever because it only occurs in workers with many years' experience and no acclimatization takes place; rather the condition tends to get progressively worse. The description by Prausnitz cannot be improved:

After working for years without any appreciable trouble except a little cough, they notice either a sudden aggravation of their cough, which becomes dry and exceedingly irritating, or peculiar attacks of breathlessness. These attacks usually occur on Mondays, whilst the rest of the week finds them in fairly good condition. For a long time the trouble may be almost or entirely limited to this "Monday fever," but gradually the symptoms begin to spread over the ensuing days of the week; in time the difference disappears and they suffer continuously.'

The same symptoms are experienced on return to work after a holiday or sometimes with the resumption of seasonal work. Malt workers for instance have told the author that they are affected by the new grain which they handle in the autumn after the summer break.

\section{Chronic Respiratory Disease}

Chronic bronchitis has been reported in workers exposed to practically all kinds of vegetable dust cotton, grain, flour, flax, hemp and even tobacco. and tea. The disease differs little from chronic bronchitis occurring in the general population in persons not unduly exposed to dust and the proving of an etiological relationship between the disease and the occupation is a matter of difficulty, almost impossible in individual cases. Unlike the pneumoconiosis caused by mineral dusts the condition has neither typical X-ray appearances nor characteristic post mortem changes. Any relationship has usually to be proved by statistical methods, either on mortality or morbidity rates for chronic lung disease. This is not an easy matter and has been carried out adequately for only a few dusts. It is not sufficient merely to collect figures for all workers in a particular industry as exposure to heavy dust concentrations, and hence the particular liability to chest disease, may be confined to a relatively small section of the workers. Sections which are favourably placed as regards dust risk may therefore mask the effects on those unfavourably placed. Cotton weavers for example are shown in the Registrar General's Occupational Mortality Supplement for 1931-2 and 192I-2 to have standardized mortality rates for respiratory disease below the average for all 
males, but the rates for cotton card room and blow room workers are much above the average.

Chronic respiratory disease due to cotton dust is known as byssinosis, and is met with particularly in card room and blow room workers. An excellent review of the literature has been made by Caminita et al. (1947). Clinically the condition is one of chronic bronchitis and emphysema with a tendency to asthma which has often supervened after a period of suffering from Monday fever. This condition, in conjunction with the clinical and industrial history is, however, deemed to be sufficiently characteristic to enable a properly constituted Medical Board to decide not only whether disability is present, but whether the disease is occupational in origin. In the latter case compensation is payable to workers who have had more than 20 years' experience and who are certified as being totally disabled*. Necropsies reveal no more than the presence of chronic bronchitis and emphysema; there is no nodulation and no cotton fibres are found in the lung.

\section{Asthma}

Acute asthma, due to allergy to a particular dust has been noted in workers exposed to very many vegetable dusts. As a rule only isolated cases are met with, those being in workers who are unduly sensitive to a particular dust. Sometimes small outbreaks are met with. Much interest was shown about 40 or more years ago in the occurrence of asthmatic symptoms in workers using South African boxwood (gonioma kamassi). Out of 112 men seen, 34 experienced difficulty in breathing (Legge, 1905, 1907), but the condition does not seem to have been a true nocturnal asthma but rather a cardiac asthma. Many of the men had other symptoms such as nausea and sickness, faintness, weakness and sleepiness, and injection of an alkaloid extracted from the wood caused rapid death from syncope in animals. Similar symptoms, probably more likely due to bronchial spasm were described by Bridge in 1935 and 1936 from Mansonia wood (sterculiacea altissima).

In 1948 the present author investigated two small outbreaks of asthma due to Western red cedar (thuja plicata). In one factory there were six cases of asthma and a seventh man was also visited who had suffered from asthma intermittently since 1922 when this wood was first introduced into the factory. Like the others affected his attacks coincided with the use of the wood, and since his retirement two years previously he had been free from further attacks. In the other factory my colleague, Dr. A. N. Currie, had found

\footnotetext{
*Compensation may now be obtained in respect of partial disability (see page 656 ).
}

two cases of asthma in 1937. At my visit I I years? later one of these cases was still working and stilif allergic to the wood, the other had died. I also examined a third case and heard of three more cases in men who had left the factory but whose? present whereabouts were unknown.

\section{Animal Dusts}

There are very few reports in the literature on음 the harmful effects of animal dusts and they must $\frac{\text { क }}{5}$ be accounted of minor importance in the pro- $\frac{\mathbb{D}}{\square}$ duction of respiratory disease. Occasionally theyo may carry infections. Pulmonary anthrax for-merly not uncommon in the West Riding of Yorkshire where it was called 'wool-sorters' $\vec{\omega}$ disease,' was due to breathing the dust arising from infected wool; the crushing of bones frome infected animals to make bone meal may carry a 3 . similar risk when sun-dried bones are used. N Sensitization effects from animal dusts have alsoin been described, for example from feathers (Bridge, 1934).

\section{Summary}

Dusts met with in industry may give rise toọa wide variety of reactions in the respiratory tract $\mathbb{Q} \mathrm{f}_{\mathbb{D}}$ workers exposed to them. The main types tabulated below:-

\section{Mineral Dusts}

I. Nose and throat irritation and ulceration: Bichromates, alkalis, arsenical compounds, etc.

2. Pneumonitis: Manganese, cadmium, etc.

3. Asthma: Salts of platinum.

4. Granulomata: Beryllium.

5. Carcinoma: Arsenic, chromates, asbestos.

6. Pneumoconiosis - (a) Without organic $\overrightarrow{\overrightarrow{0}}$ change: Iron, tin. (b) With focal emphysema: Coal, coke. (c) With fibrosis (i) Nodular: Silica; (ii) Diffuse: Asbestos.

\section{Vegetable Dusts}

r. Acute general-Mill fever: Cotton, flax, hemp, etc.

2. Acute and semi-acute respiratory (probably을 infections)-Thresher's lung, weaver's cough, bagassosis, etc.: Grain, cotton, bagasse.

3. Monday fever: Cotton, flax.

4. Chronic bronchitis and emphysemaByssinosis, hackler's cough: Cotton, flax.

5. Acute asthma: Seeds, grain, flour, wood 0 dust.

\section{Animal Dusts}

I. Acute asthma: Feathers, etc.

2. Infections: Pulmonary anthrax. 
It is suggested that the possible association of respiratory disease and occupation should be more frequently borne in mind. In doubtful cases help in investigating any such association could readily be obtained from the Medical Inspectors of the Factory Department in the case of factory workers, or the Ministry of Fuel and Power in the case of miners.

\section{Acknowledgments}

I have pleasure in acknowledging my indebtedness to my colleagues for their co-operation. Dr. E. R. A. Merewether has also lent me the X-ray film reproduced as Fig. I, Dr. F. N. R. Price those for Figs. 5 and 7 , Dr. J. M. Campbell that for Fig. 6, and Dr. Douglas Bell that for Fig. 8, for which I wish to express my thanks.

\section{BIBLIOGRAPHY}

Pneumoconiosis with Fibrosis

TALC

MCLAUGHLIN, A. I. G., ROGERS, E., and DUNHAM, K. C. (1949), Brit.'F. Ind. Med., 6, 184

MEREWETHER, E. R. A. (1933), Tubercle, 15, 69.

British Medical fournal (1948), Editorial, i, rogo.

FULLER'S EARTH

McNALLY, W. D., and TROSTLER, I. S. (1941), f. Ind. Hyg. and Tox., $23,118$.

MIDDLETON, E. L. (1940), I.L.O. Studies and Rpts., Series F.,

TONNING, H. O. (1949), f. Ind. Hyg. and Tox., 31, 4r.

SERICITE

JONES, W. R. (1933), f. Hyg., 33, 307.

Carborundum

SMITH, A. R., and PERINA, A. E. (1948), Occ. Med., 5, 396 (from Bull. Hyg., 1949, 24, 205).

Aluminium

DENNY, J. J., ROBSON, W. D., and IRWIN, D. A. (1937), Canad. Med. Ass. $¥$., 37,

GARDNER, L. U., DWORSKI, M., and DELAHANT, A. B. (1944), 7 . Ind. Hyg. and Tox., 26, 211.

GORALEWSKI, G. (1940), Arch. f. Gewerbeh. u. Gewerbep., Io, $4,384$.

GORALEWSKI, G. (194I), Ibid., I1, x, 106.

GORALEWSKI, G., and JAGER, R. (I94I), Ibid., I I, I, 102.

JAGER, R., and JAGER, F. (1941), Ibid., I1, I, 117

JOTTEN, K. W., and EICKHOFF, W. (1942), Arch. f. Hyg. $u$. Bakt., $127,5,344$.

SHAVER, C. G., and RIDDELL, A. R. (1947), f. Ind. Hyg. and Tox., 29, 145 .

GRAPHITE

DUNNER, L. (1945), Brit. F. Radiol., 18, 33.

DUNNER, L., and BAGNALL, D. J. T. (1946), Ibid., 19, 165.

DUNNER, L. (1948), Ibid., 21, 182.

GLOYNE, S. R., MARSHALL, G., and HOYLE, C. (1949),

Thorax, 4 , 31.
HARDING, H. E., and OLIVER, G. B. (1949), Brit. F. Ind. Med., 6, 91 .

PNEUMOCONIOSIS Without FibRosis

ARRIGONI (1933), Med. d. Lavoro, 24, 46r.

BARRIE, H. J., and HARDING, H. E. (1947), Brit. F. Ind. Med., BRITTON, J. A., and WALSH, E. L. (1940), F. Ind. Hyg. and Tox., COLLEN, M. F., DYBDAHL, G. L., and O'BRIEN, G. F. (1944), Ibid., 26, 1 .

COLLEN, M. F. (1947), Ibid., 29,113

DOIG, A.'T., and MCLẢUGHLIN, A. I. G. (1936), Lancet, 1, 771

DOIG, A. T., and MCLAUGHLIN, A. I. G. (r948), Ibid., I, 789.

ENZER, M., and SANDER, O. A.'(1938), F. Ind. Hyg. and Tox., 20, 333 .

ARDNER, L. U., DURKAN, T. M., BRUMFIEL, D. M. and SAMPSON, H. L. (1939), $\mathscr{F}$. Ind. Hyg. and Tox., 21, 279.

GROH, J. A. (1944), Ind. Med., 13, 508 .

HARDING, H. E. (1948), Brit. F. Ind. Med., 5,70

HARDING, H. E., GROUT, J. L. A., and LLOYD DAVIES, T. A. (1947), Ibid., 4, 223 .

INTERNATIONAL LABOUR OFFICE (1933), Occupation and Health.

LANZA, A. J. (1945), 7. Missouri Med. Ass., 42, 765 (from Occ. Med., 1946, 1, 193).
MCLAUGHLIN, A. I. G., GROUT, J. L. A., BARRIE, H. J., and HARDING, H. E. (1945), Lancet, 1,337 .

PENDERGRASS, E. P., and PRYDE, A. W. (1948), f. Ind. Hyg. and Tox., 30, 119.

SANDER, O. A. (1944), F. Ind. Hyg. and Tox., 26, 79.

PNeUMONitis

LLOYD DAVIES, T. A. (1946), Brit. F. Ind. Med., 3, 111 .

LLOYD DAVIES, T. A., and HARDING, H. E. (I949), Ibid.

ROYSTON, G. RIDDELL (1949), Brit. Med. f., 1, 103०.

Delayed Pneumonitis

AGATE, J. N. (1948), Lancet, 2, 530 .

GARDNER, L. U. (1946), Trans. Eleventh Ann. Meeting Ind. Hyg. Foundation (November) p. 88 (from f. Ind. Hyg. and Tox., 29, abs. 71).

HARDY, H. L., and TABERSHAW, I. R. (1946), f. Ind. Hyg. and Tox., 28, 197.

LUNG CANCER

AMOR, A. J. (1938), Rept. Eighth Internat. Congress on Ind Accidents and Occ. Diseases, Leipzig, 1939, 2, 248.

CURRIE, A. N. (1947), Brit. Med. Bull., 4, 402. GROSS, E., and KOELSCH, F. (1943), Arch. f. Gewerbep. u.

HARTING, F. H., and HESSE, W. (1870), Vierteljahresschr. fo gerichtl. Med., 30, 296; 31, 102 (from TELEKY, L. (1937), f. Ind. Hyg. and Tox., 19, 73).

HILL, A., BRADFORD, and FANNING, E. L. (1948), Brit. $\mathcal{F}^{\circ}$ Ind. Med., 5, 2.

MACHLE, W., and GREGORIUS, F. (1948), P.H. Rpts., 63, 35

MEREWETHER, E. R. A. (1949), Ann. Rpt. Chief Insp. of Factories

for 1947, p. 79.

AsthMa

HUNTER, D., MILTON, R., and PERRY, K. M. A. (1945), Brit. $\mathscr{F}$. Ind. Med., 2, 92.

Vegetable Dusts

BRIDGE, J. C. (1928), Ann. Rpt. Chief Inspector of Factories,

p. 96. J. C. (1935), Ibid., p. 60.

BRIDGE, J. C. (1936), Ibid., p. 56.

BRIDGE, J. C. (1934), Ibid, 66

CAMINITA, B. H., BÄUM, W. F., NEAL, P. A., and SCHNEITER, R.' (1947), Pub. Health'Bull., No. 297

CAMPBELL, J. M. (1932), Brit. Med. F., 2, 1143.

COLLIS, E. L. (1913), Ann. Rpt. Chief Inspector of Factories, p. 150.

FAWCITT, R. (1936), Brit. F. Rad., 172 and 354.

HOFFMANN, W. (1946), Schweiz. Med. Wschr., 76, 988 (from Brit. F. Ind. Med. 1947, 408 )

HUNTER, D., and PERRYY, K. M. A. (1946), Brit. F. Ind. Med., 3,

LEGGE, T. M. (1905), Ann. Rpt. Chief Insp. of Factories, p. 380.

LEGGE, T. M. (I907), Ibid., p. 248.

MCNAIR, L. C., and MIDDLETON, E. L. (1924), Ann. Rpt. Chief Inspector of Factories, p. 106.

PRAUSNITZ, C. (1936), Med. Res. Council, Spec. Rpt. Series,

SCHNEITER, R., REINHART, W. H., and CAMINITA, B. H. (1948), $\mathcal{F}$. Ind. Hyg. and Tox., 30, 238.

TORNELL, E. (1946), Act. Med. Scand., 125, 191 (from Brit. $\mathcal{F}$. Ind. Med., 1947, 4, 108).

TOWEY, J. W. (r933), Wisconsin Med. 7., 773. 